\title{
Smartphone application for Self - Management Diabetes: A review
}

\author{
Eimad Eldin Abusham ${ }^{1}$, Aisha Mohammed Ahmmed Al-Za'abi ${ }^{2}$ \\ ${ }^{1,2}$ Faculty of Computing and Information Technology, Sohar University, Oman, PO Box 44, Sohar, PC 311 \\ EAbusham@su.edu.om ${ }^{1}$, azaabi@soharuni.edu.om ${ }^{2}$
}

\begin{abstract}
In these days, Smartphone application plays an important role that has an impact effect on the users. Cell phones are an essential tool in our daily lives because they provide many communication and fun services. Therefore, it can be a powerful tool for helping the patient who has diabetes. This research paper aims to develop a smartphone application for the self-management of diabetes patient activities. It also seeks to monitor the diabetes patient status and through the smartphone application. The paper reviews the available applications on the smartphone and articles published in the online resources database. The review papers covered various applications to support the selfmanagement tasks such as diet, blood testing, education, exercises, alter, etc. The critical analysis indicates that mobile applications have been improving patients' positive behavior to have the self-management of diabetes. Using the application is a handy tool to change the attitude in self-care activities related to diabetes management and increased user stratification.
\end{abstract}

Keywords: smartphone application; management Information; diabetes; self-care management; Healthcare. 


\section{Introduction}

Diabetes are types of chronic illness that need to take care full about the medical and support patients to have educational about self-management. Also, it supports to decrease the period term disability risk and keep from complication (American Diabetes Association, 2016). In the review, self-controlling refers to duties that an individual should do it to live better with one or more of chronic diseases. When the patients do this tasks that will increase the confidence to deal with any medical management. These tasks include gain confidence to deal with medical management and emotional management (Adams, Greiner, \& Corrigan, 2004). The operation of the self-management need to the basic data that help the patients have behavior of controlling. When smartphone technologies increase, the promotion and adoption will increase. The tools that use to control diabetes follows various steps like pre-processing (Abusham et al., 2008; Abusham \& Wong, 2009), feature extraction and classification (Abusham \& Bashier, 2013; Abusham 2014) and any other of chronic disease reports in many of literature and been on the internet (Årsand, Tatara, \& Hartvigsen, 2011). Image enhancement and vision systems are used in data-visualization applications to improve images' quality to facilitate medical images or reports interpretation (Al-Hatmi \& Yousif, 2017; Hasoon et al., 2011).

According to the reviewed, there are different types of applications with different functionalities available on online uses in different of literate (Chomutare, Fernandez-Luque, Årsand, \& Hartvigsen, 2011). While, other reviewed the diabetes application available on play store and apple with the flexibility and easy to use (Martin, Flood, Sutton, Aldea, Harrison, \& Waite, 2011). This study will continue the review through the functional and nonfunctional that need to evaluate the requirements. Also, this paper will study the issues that needed for wide adoption of such interventions. This study aims to identify the review diabetes applications that have been helping patients to have selfmanage in their conditions. In practice, the analysis found the basic features and the important requirements of selfmanaging diabetes application. Theoretically, the results of research find the gaps which help outline research agenda on various factors, improve the adoption, ease of use and integration of the diabetes self-management application into patient's daily routine.

\section{Methodology}

This paper deployed a qualitative descriptive design based on the selected literature review of online vendor markets related to diabetes mobile applications. A critical analysis and comparison of selected studies are implemented to record the features that impact diabetes patients. The method is including two stages as follows: 


\subsection{Strategic research}

The research strategy is an important point to study the research planning to design a smart application for selfmanagement of diabetes patients. Figure 1 illustrates stages of strategic research in this paper.

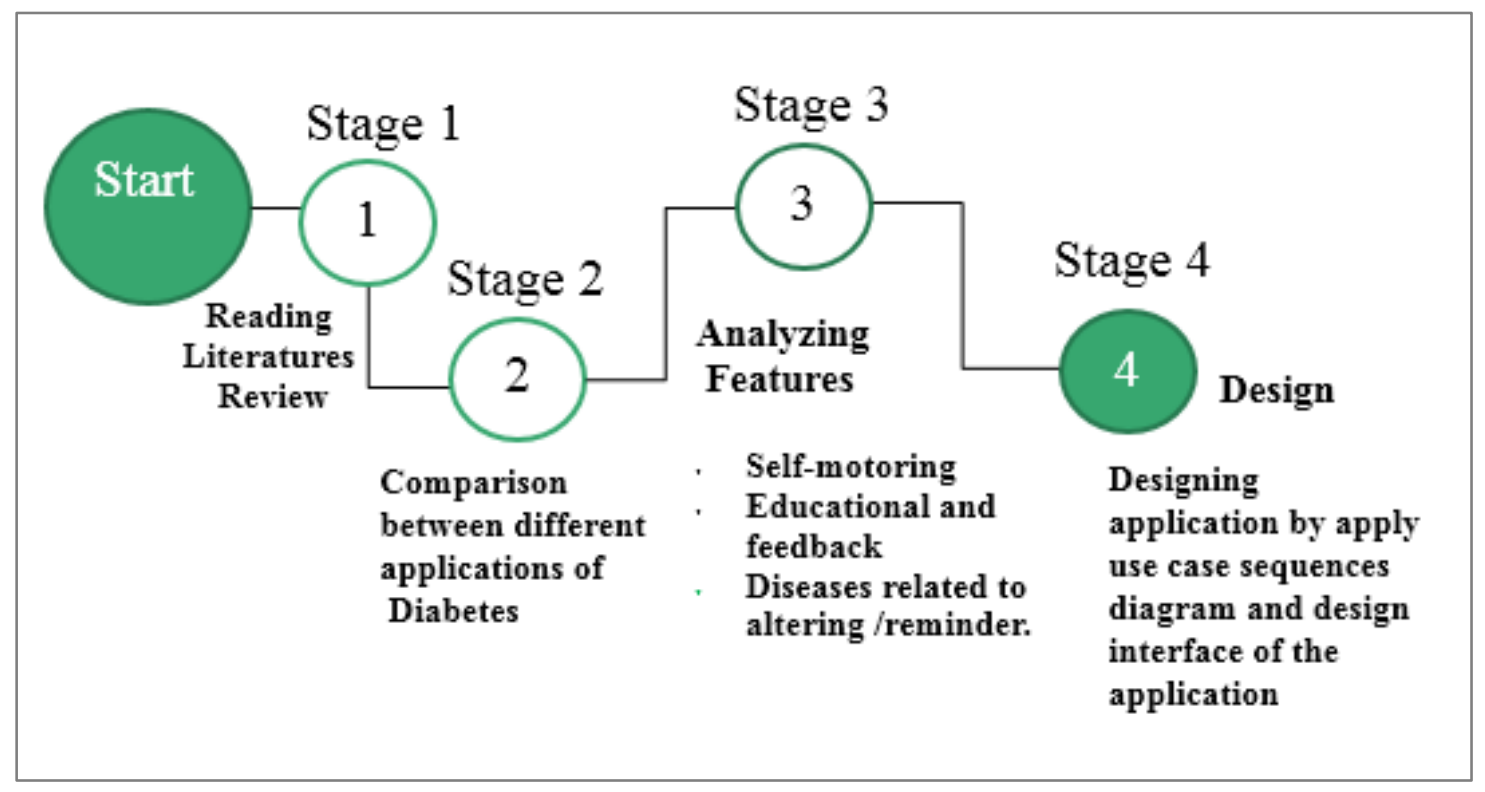

Figure 1: Stages of strategic search

The literature review methodology is the first stage used to provide evidence to decision makers in the health care. Also, the article is based on study various of applications available on the smartphone. The search was contacted between September 2017 and November 2017 for the article published in peer review journals using multiple of database including PubMed, EBSCO, IEEE, Springer and ACM database that uses the keyword of application diabetes smartphone from the literature reviewed the following criteria which including:

- The patient as a primary user is intended for applications.

- The application should have tasks for self-management diabetes

The second stage is collection types of application related to diabetes and compare between them. The third stage is analyzing the features which include self-motoring, educational and feedback and diseases related to altering/reminder. The fourth stage is designing the application that includes the interface and database needed in the application. The last stage is implementation that will develop the application by using the program such as android studio. 


\subsection{Requirements and user analysis}

This study developed a smartphone application for self-management diabetes to support the patients with diabetes for daily care. The application includes the services that can take care about their health. Services accomplished in the application for the patients to manage diabetes by using mobile. Figure 2 illustrates the overall the framework of the application which performs two sides of patients and admin care management.

\subsubsection{Patients Side}

- Increase self-care management knowledge and skills related to diabetes care.

- Recording personal activities relevant to diabetes such as glucometer testing, doctors \&appointments, medicine and blood pressure.

2.2.2. Admin Care management side

- Control the applications which health conditions of the patient.

- Control the alerting at the system.

- Control the risk management at the application.

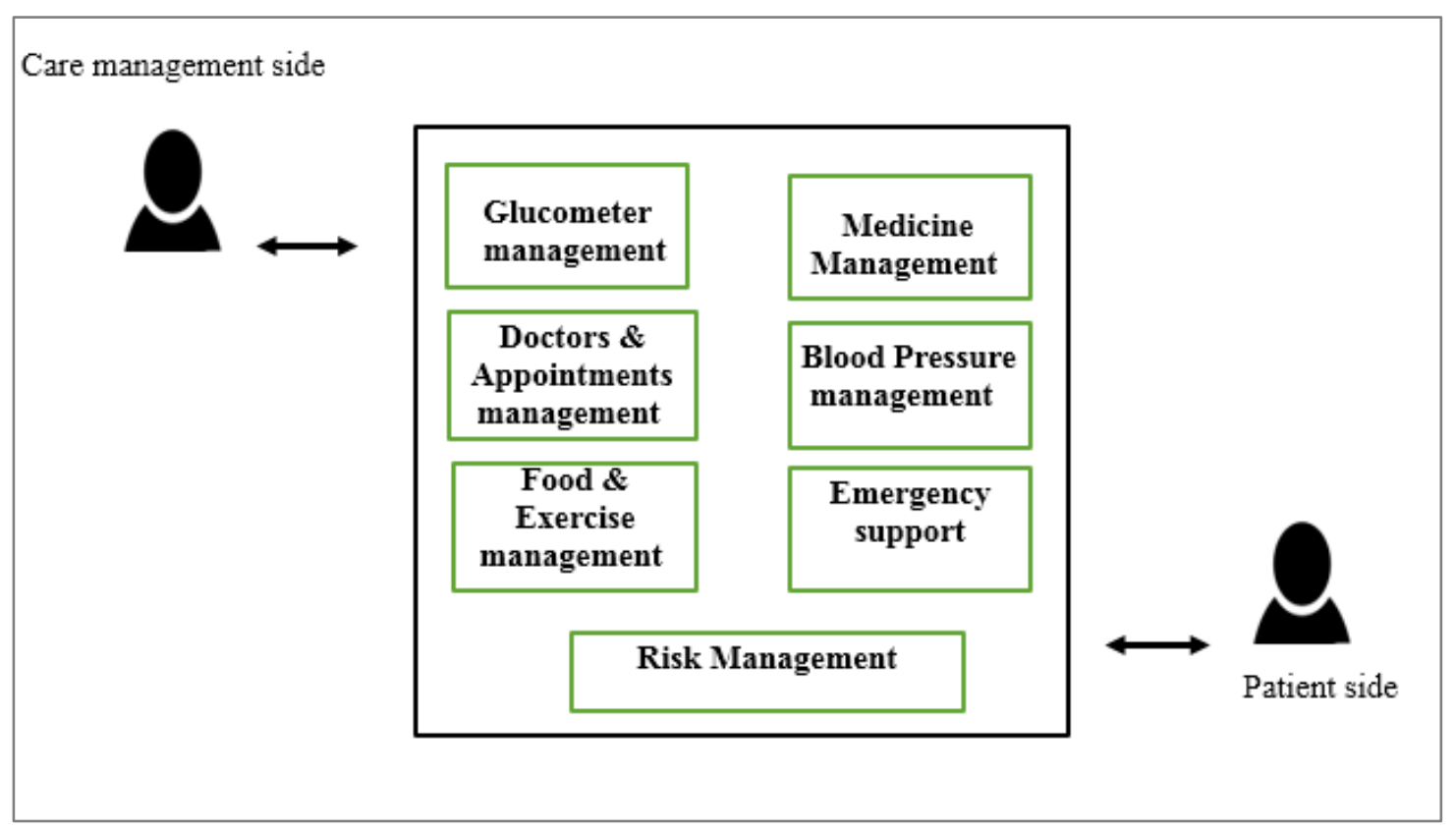

Figure 2: Framework of self - management diabetes application 
The system segmented into serval functions which include Glucometer management, Medicine management, blood pressure management, food and exercise management, emergency support and risk management.

\section{Modeling and prototype:}

Modeling and prototype will use to describe the functional requirements of diabetes management and condition for the prosed solution which include Use case and sequence diagrams.

\subsection{A sequence diagram of Diabetes management application}

A sequence diagram is dynamic modeling focuses on the interaction occurring in the application and how the object can interact with others in order. Figure 3 illustrates the patient navigates to profile after successful login. After that, the application will show the diabetes application main page. Then, the patient can be recording the personal information such as such as Glucometer, doctors, appointments, medicine tracker, blood pressure, view food and exercises. After that, the application displays the information from the database store. Also, the application includes additional features such as report, setting and feedback. This application will be free and available for anyone in the smartphone. In addition, the application allows easy accessing and saving for glucometer, doctors, appointments, medicine and blood pressure with a reminder. The care management that is responsible for the application.

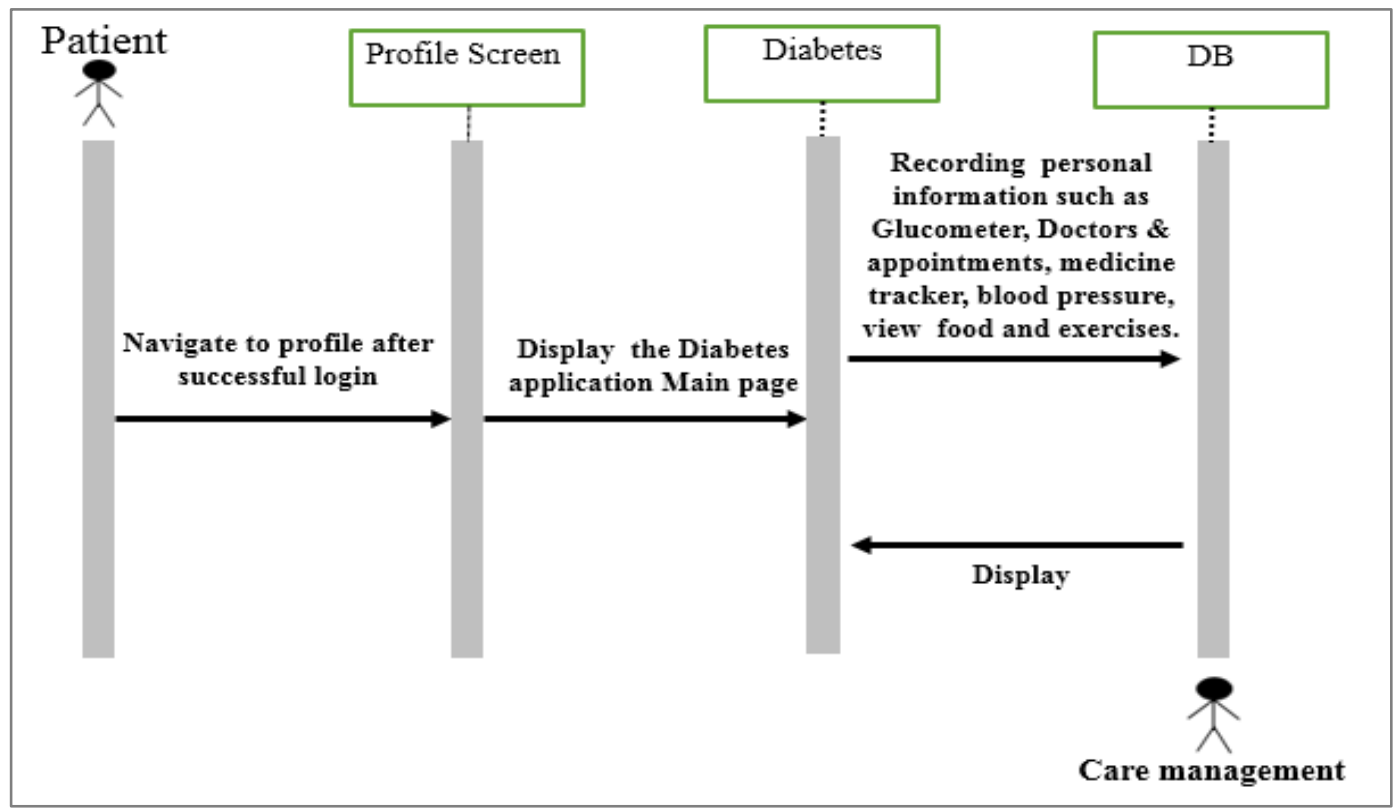

Figure 3: A sequence diagram of diabetes of self- management application 


\subsection{Use case of Self - Management Diabetes application}

Actors and use cases show the details description of interaction between users and application. There are two actors which are patient and admin care management. First actor is patient. Figure 4 presents the use case of patient actors. It contains several tasks that include register, login, create profile, add, delete, setting reminder, view report, send feedback and logout. Figure 5 presents the use case of the care management actors and the table 1 describes for each use case.

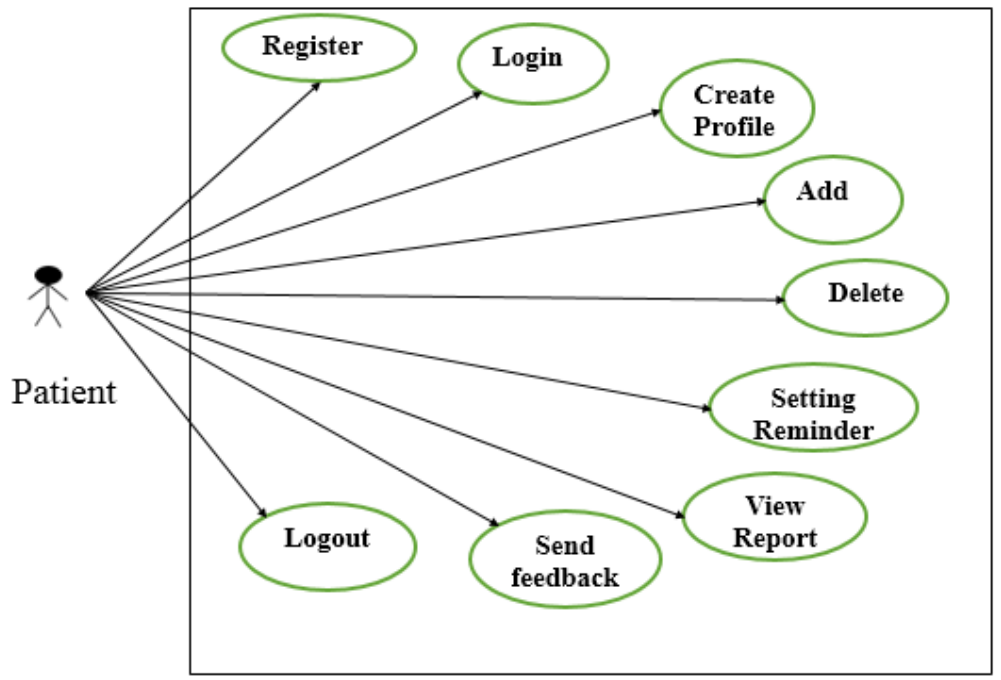

Figure 4: Use case for patient

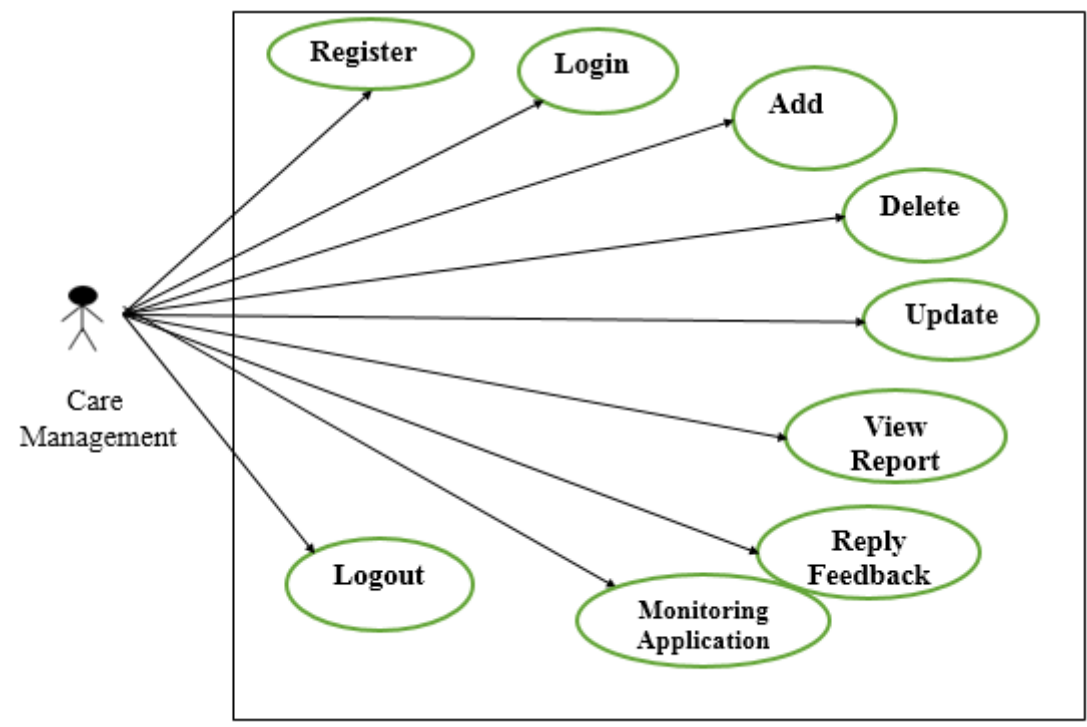

Figure 5: Use case for care management 
Table 1: The description of actors

\begin{tabular}{|c|c|c|}
\hline Actor & Use case & Use case description \\
\hline \multirow{4}{*}{ Patient } & Register & The patient should register to the application. \\
\hline & Login & $\begin{array}{l}\text { The patient has authenticated which needs login to } \\
\text { application. }\end{array}$ \\
\hline & Create profile & The patient can add personal information. \\
\hline & Add, Delete & $\begin{array}{l}\text { Patients can be recording the personal information such as } \\
\text { such as Glucometer, Doctors \& appointments, medicine } \\
\text { tracker, blood pressure. }\end{array}$ \\
\hline \multirow{10}{*}{$\begin{array}{l}\text { Care } \\
\text { management } \\
\text { (admin) }\end{array}$} & Setting & The patient can set the reminder, etc. \\
\hline & View report & The penitent can view the report for his testing. \\
\hline & Send feedback & The patient can send feedback through the application. \\
\hline & Logout & Exit from the application. \\
\hline & Register & The admin should register to the application. \\
\hline & Login & $\begin{array}{l}\text { The admin has authenticated which needs login to } \\
\text { application. }\end{array}$ \\
\hline & Add, Delete, update & The admin can add, delete and update in the application. \\
\hline & View report & The admin can view the report of the application. \\
\hline & Reply feedback & $\begin{array}{l}\text { The admin replies to patient feedback through the } \\
\text { application. }\end{array}$ \\
\hline & Logout & Exit from the application. \\
\hline
\end{tabular}

\subsection{Implementation tools and user interface design for Self - Management Diabetes}

The implementation process will be after the design specifications. The implemented design tool in the application which included the eclipse android connects with database. SQLite database will has implemented in design management for the applications which support the patient to access and use the services in the application.

\subsection{Interface design of Self - Management Diabetes:}

Diabetes management application is used for the diabetes self-management that records personal information such as Glucometer, doctors \& appointments, medicine tracker, blood pressure, and view food and exercises. Also, the application contains additional features such as report, setting and feedback. This application is free and available for everyone. Additionally, the application allows easy access to save the Glucometer, doctors, appointments, medicine and blood pressure with a reminder. Figure 6 illustrates a login activity that the user can access the application by using user name and password. If the user does not have the account, can registe by using register activity to access in the application. Figure 7 illustrates the register acrivity for the user . Figure 8 illustrates the home activity that the user can access the page, when enters the user name and password. This page will view all the 
services that available in the application. Figure 9 illustrates Glucometer activity. The user can record the test result and inters in the application. The patient can add the description of the medicine and also add the reminder for the medicine time. Figure 10 illustrates the medicine activity that the patient can add the description of the medicine and can add a reminder for the medicine time. Figure 11 is the feedback activity. The patient can send feedback to the care management.

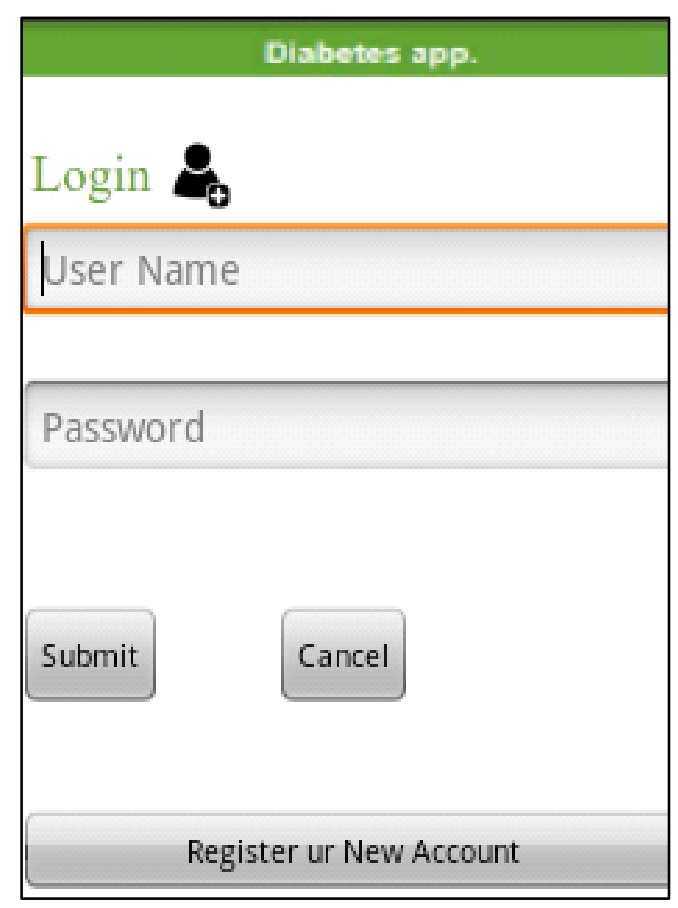

Figure 6:The Login activity of the proposed application

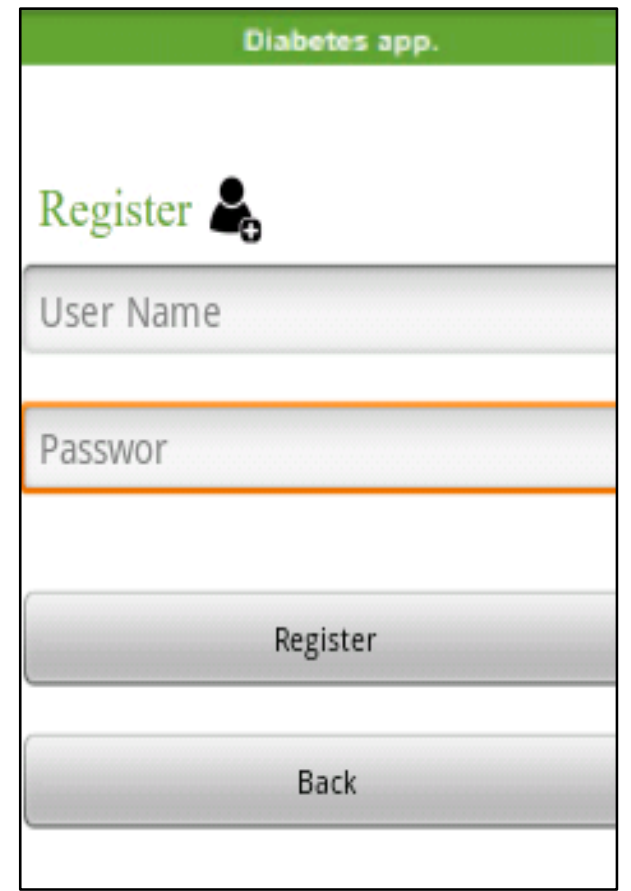

Figure 7: Register activity of the proposed application 


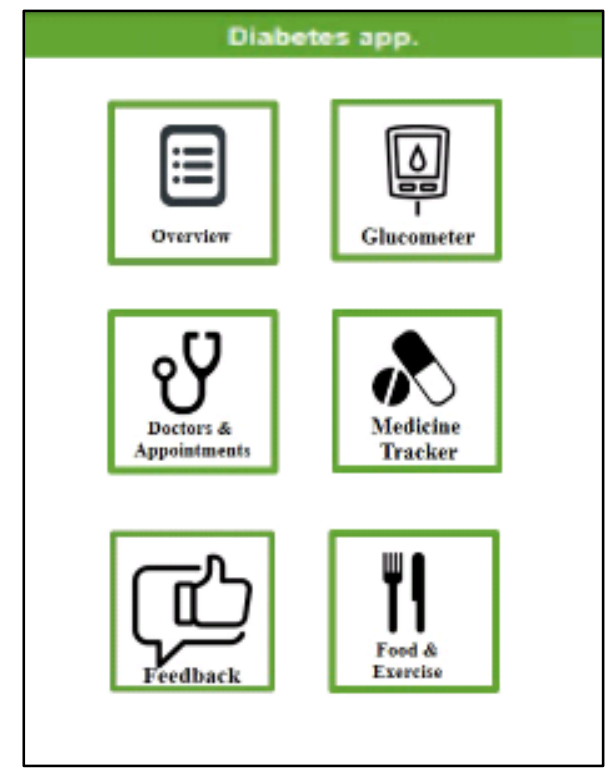

Figure 8: The Home activity of the proposed application

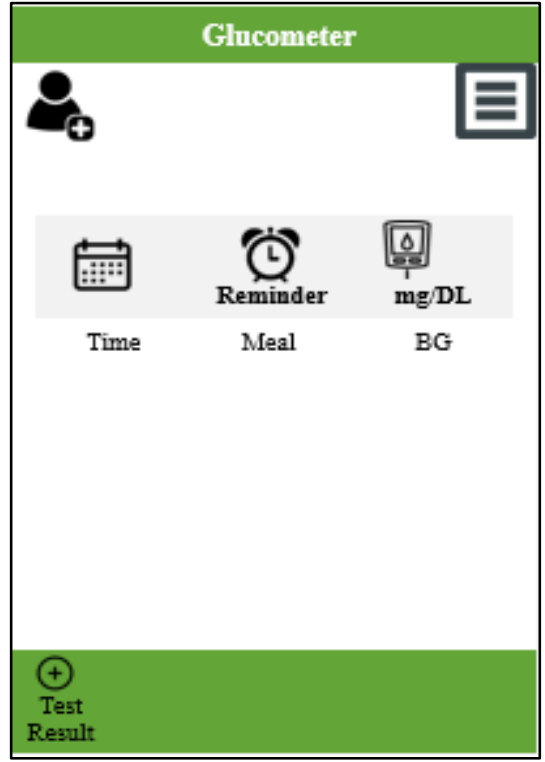

Figure 9: Glucometer activity of the proposed application

Figure 12 illustrates the food and exercises activity. The application supports the education about food and exercise that has the benefits for the patients. Figure 13 illustrates the doctor profile activity. The patient can add the basic information to contact with him.

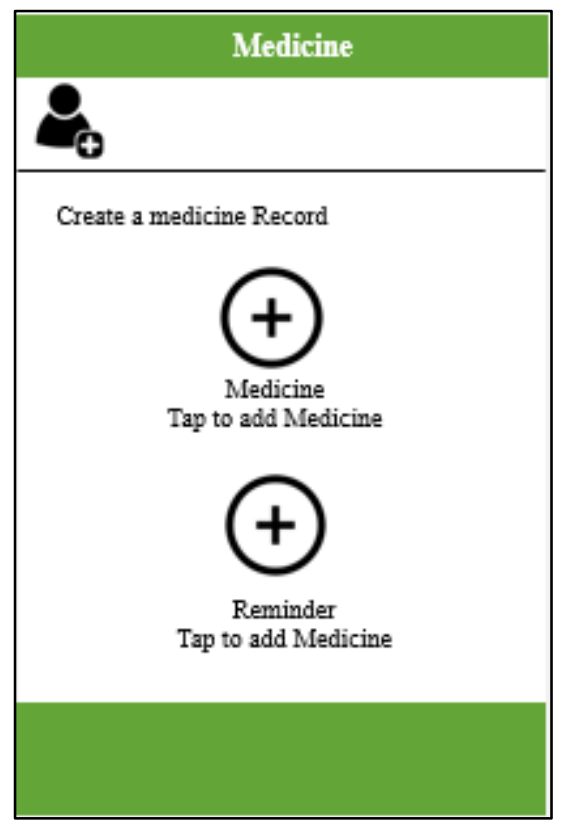

Figure 10: The Medicine activity of the proposed application

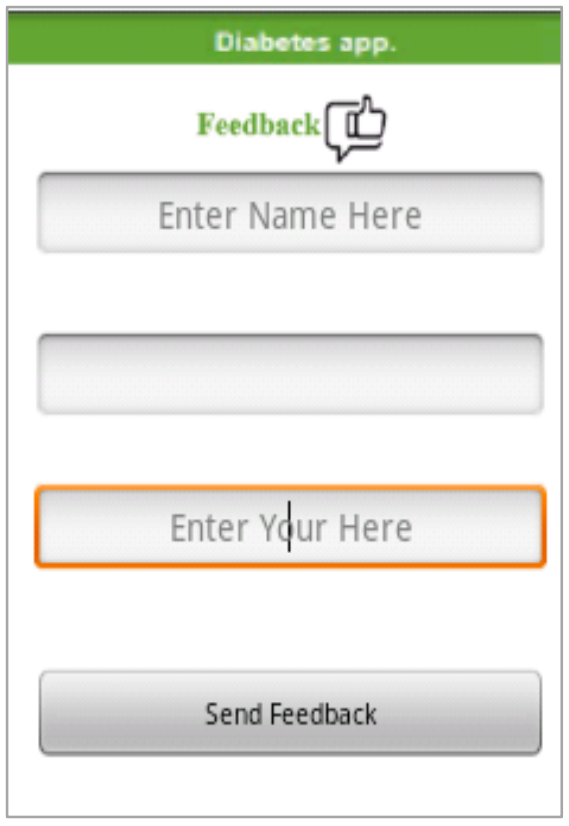

Figure 11: The feedback activity of the proposed application 


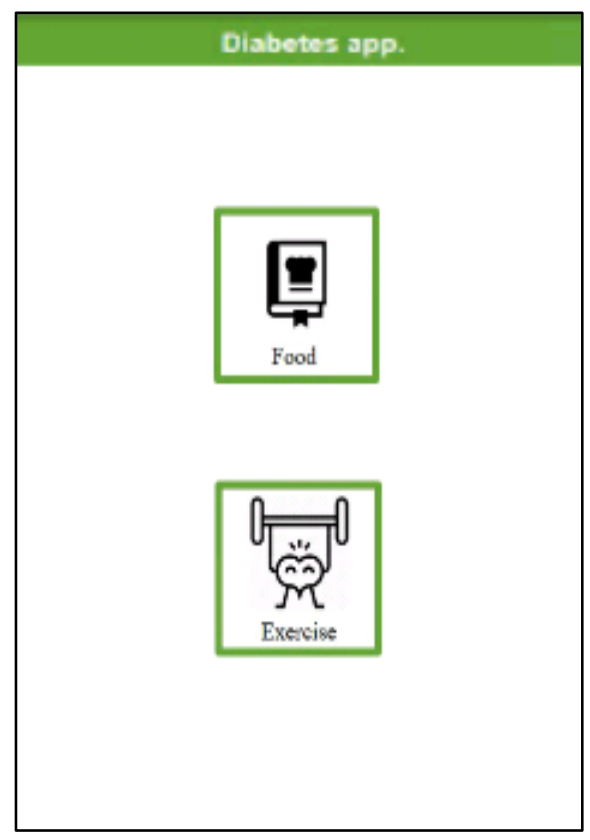

Figure 12: The Food and exercises activity of the proposed application

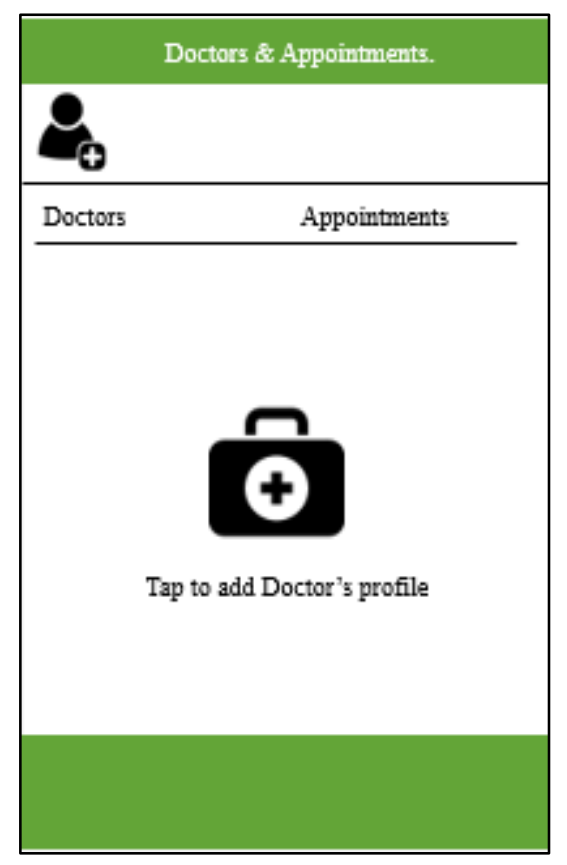

Figure 13: Doctors Profile information

\section{Results \& Discussions}

The search in Google scholar related to ("Mobile application" + "Diabetes") criteria provided the result of 14,300 for the period from 2010 to 2020 and obtained a result of 2457 in the Science Direct directory. Figure 14 presents the full result for several directories.

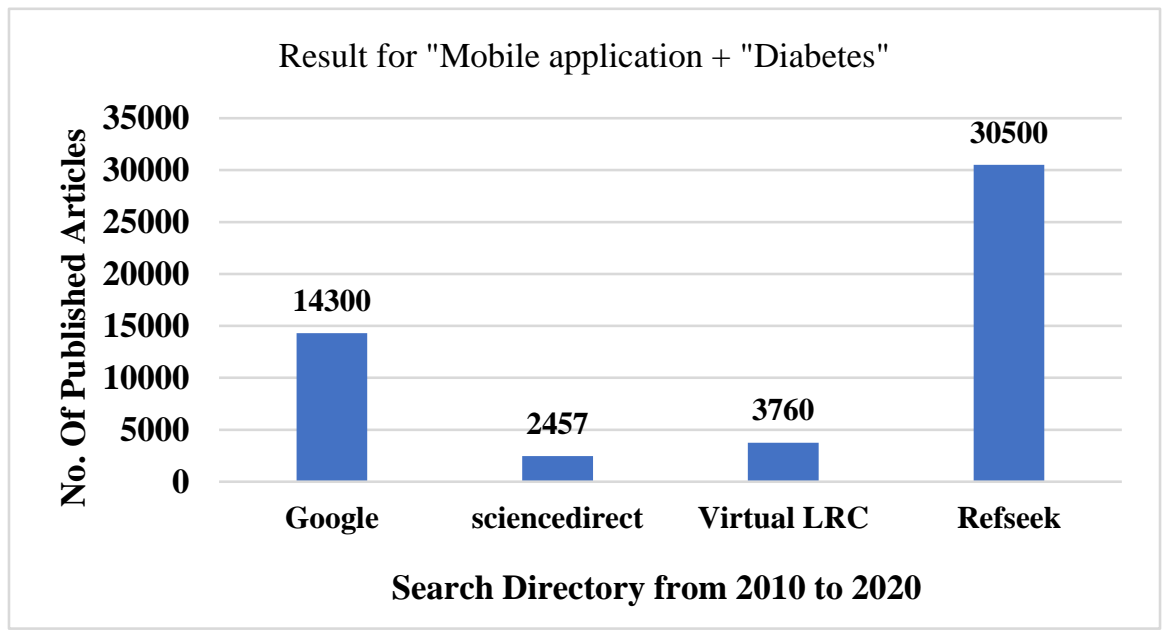

Figure 14: Results for "Mobile application + "Diabetes" criteria 
Thirty-nine percentage of the applications are available in the play store and apple. Theses application supports different tasks which include diet, physical exercises, medication, blood testing etc. In addition, the tasks of the literature which includes education, feedback, weight management, blood presser monitoring (American Diabetes Association, 2016; Chomutare, Fernandez-Luque, Årsand, \& Hartvigsen, 2011; Sibal, \& Home, 2009). Other support tasks included decision support; notification alters. Table 2 is reported the percentage of applications which support self-management diabetes. Table 3 is a list of the application and their functionalities. In this paper, the application has different services which include to record medication, Blood Glucometer measurement, physical exercise and other notes the patients can add it (Quinn, Shardell, Terrin, Barr, Ballew, \& Gruber-Baldini, 2011). The results from the studies, the smartphone applications have a positive effect on developing health behavior (Årsand, Tatara, Østengen, \& Hartvigsen, 2010).

Table 2: Reported the percentage of applications

\begin{tabular}{lcc}
\hline Function & Application (\%) & Literature (\%) \\
\hline Blood Gluer & 100 & 90 \\
Medication & 79 & 48 \\
diet & 70 & 85 \\
Physical exercises & 49 & 55 \\
Education & 20 & 36 \\
Weight & 35 & 18 \\
Blood Pressure & 35 & 28 \\
\hline
\end{tabular}

Table 3: List of application and their functionalities.

\begin{tabular}{lccccc}
\hline Application & $\begin{array}{l}\text { Blood } \\
\text { Glucometer }\end{array}$ & $\begin{array}{l}\text { Physic } \\
\text { exercises }\end{array}$ & diet & Medication & Blood Pressure \\
\hline $\begin{array}{l}\text { Diabetes } \\
\text { Buddy Lite }\end{array}$ & YES & YES & YES & YES & NO \\
$\begin{array}{l}\text { Diabetes } \\
\text { diary }\end{array}$ & YES & NO & YES & YES & NO \\
$\begin{array}{l}\text { Diabetes } \\
\text { manger }\end{array}$ & YES & NO & YES & YES & YES \\
Easy diabetes & YES & NO & YES & YES & NO \\
& & & & & \\
\hline
\end{tabular}


Many studies show the positive effect of mobile health intervention in the management of chronic diseases (Sibal, \& Home, 2009; Preuveneers, \& Berbers, 2008; Årsand, Tatara, Østengen, \& Hartvigsen, 2010). The literature indicate that mobile application can be useful tools for diabetes self-management (Kollmann, Riedl, Kastner, Schreier, \& Ludvik, 2007; Quinn, Shardell, Terrin, Barr, Ballew, \& Gruber-Baldini, 2011). The reviews indicate that selfmanagement diabetes is useful to patients and provider. Using smartphone application led to improve the health like Blood glucometer, increase the psychical exercises, healthy diet, etc. In many cases appeared like an electronic version of paper-based log book system which reduces the perceived benefits to patients (especially less skilled in technology). The growth in technology capabilities of smartphones coupled with cloud computing provide unprecedented opportunities to expend decision support and analysis capabilities in hand end users. Emerging evidence suggests that smartphones are making a positive change in the management of chronic diseases including diabetes. The research also showed a high level of user satisfaction and had a positive impact on self-management diabetes. In addition, the paper showed the smartphone application of diabetes that improves self-management of diabetes is grates when a user satisfies is high.

\section{Conclusion}

In conclusion, the smartphone plays an important role in controlling chronic diseases of patients. The current study provides a description of building of the application for self-management diabetes. Where previous studies have demonstrated the importance of applications' functionality to improve the health and comfort of diabetic patients. The findings conclude that applications lead to positive changes in self-care activities related to diabetes management. The analysis suggests that applications improve a positive self-management behavior for diabetes. Using the app is a very useful attitude change tool in self-care activities related to diabetes. management.

\section{Acknowledgment}

The research leading to these results has no Grant Funding.

\section{References:}

[1]. Adams, K., Greiner, A. C., \& Corrigan, J. M. (2004). The 1st annual crossing the quality chasm summit: a focus on communities.

[2]. Abusham, E. E. A., \& Bashier, H. K. (2013, August). Face recognition using local graph theory (LGT). In 2013 international conference on computing, electrical and electronic engineering (ICCEEE) (pp. 593-596). IEEE. 
[3]. Abusham, E. E., \& Wong, E. K. (2009). Locally linear discriminate embedding for face recognition. Discrete Dynamics in Nature and Society, 2009.

[4]. Abusham, E. A. (2014, August). Face verification using local graph structure (LGS). In 2014 International Symposium on Biometrics and Security Technologies (ISBAST) (pp. 79-83). IEEE.

[5]. Abusham, Eimad EA, et al. "Face recognition based on nonlinear feature approach." (2008).

[6]. Al-Hatmi, M. O., \& Yousif, J. H. (2017). A review of Image Enhancement Systems and a case study of Salt \&pepper noise removing. International Journal of Computation and Applied Sciences (IJOCAAS), 2(3).

[7]. American Diabetes Association. (2016). Standards of medical care in diabetes - 2016 abridged for primary care providers. Clinical diabetes: a publication of the American Diabetes Association, 34(1), 3.

[8]. Årsand, E., Tatara, N., \& Hartvigsen, G. (2011). Wireless and mobile technologies improving diabetes selfmanagement. In Handbook of Research on Mobility and Computing: Evolving Technologies and Ubiquitous Impacts (pp. 136-156). IGI Global.

[9]. Årsand, E., Tatara, N., Østengen, G., \& Hartvigsen, G. (2010). Mobile phone-based self-management tools for type 2 diabetes: the few touch applications. Journal of diabetes science and technology, 4(2), 328-336.

[10]. Chomutare, T., Fernandez-Luque, L., Årsand, E., \& Hartvigsen, G. (2011). Features of mobile diabetes applications: review of the literature and analysis of current applications compared against evidence-based guidelines. Journal of medical Internet research, 13(3), e65.

[11]. Hasoon, F. N., Yousif, J. H., Hasson, N. N., \& Ramli, A. R. (2011). Image Enhancement Using Nonlinear Filtering Based Neural Network. Journal of Computing, 3(5), 171-176.

[12]. Kollmann, A., Riedl, M., Kastner, P., Schreier, G., \& Ludvik, B. (2007). Feasibility of a mobile phone-based data service for functional insulin treatment of type 1 diabetes mellitus patients. Journal of medical Internet research, 9(5), e36.

[13]. Martin, C., Flood, D., Sutton, D., Aldea, A., Harrison, R., \& Waite, M. (2011, September). A systematic evaluation of mobile applications for diabetes management. In IFIP Conference on Human-Computer Interaction (pp. 466-469). Springer, Berlin, Heidelberg.

[14]. Preuveneers, D., \& Berbers, Y. (2008, September). Mobile phones assisting with health self-care: a diabetes case study. In Proceedings of the 10th international conference on Human computer interaction with mobile devices and services (pp. 177-186).

[15]. Quinn, C. C., Shardell, M. D., Terrin, M. L., Barr, E. A., Ballew, S. H., \& Gruber-Baldini, A. L. (2011). Clusterrandomized trial of a mobile phone personalized behavioral intervention for blood glucose control. Diabetes care, 34(9), 1934-1942.

[16]. Sibal, L., \& Home, P. D. (2009). Management of type 2 diabetes: NICE guidelines. Clinical medicine, 9(4), 353. 